
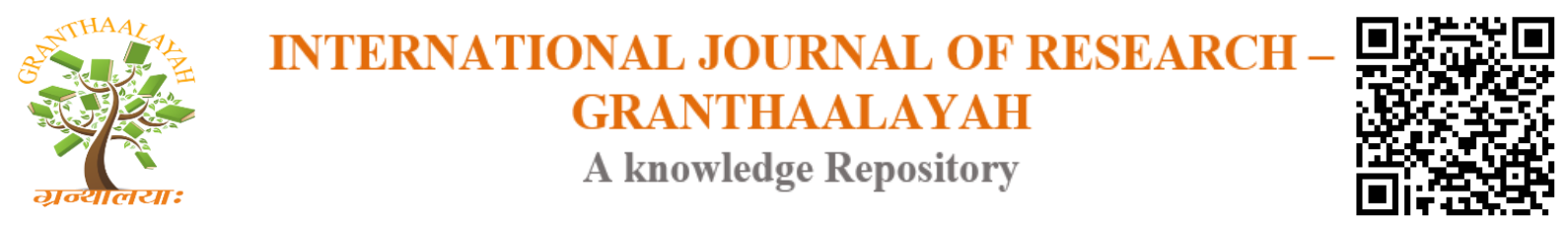

Science

\title{
EFFECTIVENESS OF FOLK MATHEMATICS ON ACHIEVEMENT AT SECONDARY LEVEL STUDENT
}

\author{
Mrs. K. K. Sumathi ${ }^{* 1}$ \\ ${ }^{* 1}$ M.Sc. (Maths), M.Phil., M.Sc (Psy)., M.Ed., M.Phil., NET(Edu)., Assistant Professor of \\ Psychology, Sasurie College of Education, Vijayamangalam, Tiruppur District, INDIA
}

DOI: https://doi.org/10.29121/granthaalayah.v4.i10(SE).2016.2463

\begin{abstract}
The present study is aimed at finding the effectiveness of folk mathematics on achievement at secondary level student. It was an experimental method conducted on secondary school students in teaching mathematics for seventh standard. The result concluded by the investigator was that the effect of folk mathematics was better than the traditional method of teaching.

Keywords:

Mathematics, Education, Student, Achievement \& Experimental Method.

Cite This Article: Mrs. K. K. Sumathi, "EFFECTIVENESS OF FOLK MATHEMATICS ON ACHIEVEMENT AT SECONDARY LEVEL STUDENT" International Journal of Research Granthaalayah, Vol. 4, No. 10: SE (2016): 14-20.
\end{abstract}

\section{INTRODUCTION}

\section{FOLK METHOD}

"It has well been said that the highest aim in education is analogous to the highest aim in mathematics, namely to obtain not results but powers, not particular solutions but the mean by which endless solutions may be wrought"

George Eliot

Majority of the children are enrolled into school but are forced to drop out because they are unable to cope with the demands of school and find studies 'uninteresting 'or 'difficult'. The way teaching is designed by their textbooks and teachers alienates them, not allowing them to use their rich life experiences, and they are soon mad to believe that they have no brains. It is now becoming clear that if our teaching strategies in elementary school had been more sensitive and relevant in these past fifty years we would not have faced such a stupendous task of making millions literate through mass literacy campaigns. The last decade has witnessed a loud cry from 
a large number of students who suffer from deep math anxiety and are incapable of solving simple arithmetical problems. A major reason for children doing less well in school mathematics seems to be the ay the subject is taught in schools in India at the primary level. The classroom teaching is completely divorced from their everyday experiences and knowledge.

It is common experiences with all of us that we "learn" when we experience sense of joy while involving ourselves in an activity. This kind of learning is thrilling in that it is natural and spontaneous. The social setting in which such natural learning occurs involves the learning cultures. Learning cultures facilitate the individuals and the community as a whole in finding a way of life. Functionalism is central to whatever is learnt. In fact, the acceptance of the idea that mathematical knowledge is part of the culture has been fairly half-hearted among the policymakers and the textbook writer. Though anthropological rand socio-historical research strengthens this view by revealing more and more of the rich tapestry of mathematical knowledge existing in hundreds of folk cultures around the world, there is a kind of inbuilt resistance to linking mathematics teaching to community knowledge. Six operations which people engage in across all cultures are counting, measuring, designing, locating, playing and explaining (Dorfler 2000). These activities involve an enormous amount of mathematics. In fact mathematics understanding is culturally conditioned. The philosophic trust of mathematics educations as spelt out in the National Curriculum Frameworks (NCF 2000)is aimed at encouraging students to explore mathematics concepts and solve problems related to their everyday experiences. Even today, the emphasis in school math is entirely on conceptual understanding, application of concepts, algorithmic performance, problem -solving process and so on. The attitudinal ad other affective aspects of mathematics learning are to a large extent undermined; leave aside the inclusion of the everyday mathematical cognitions of the children in textbooks and classroom transactions.

According to NCF2005, vision for school mathematics is:

- Children learn to enjoy mathematics rather than fear it

- Children see mathematics as something to talk about, to communicate, to discuss among themselves to work together on

- Children pose and solve meaningful problems

- Children use abstractions to perceive relationships, to see structure, to reason out thing to argue the truth or the falsity of the situations

- Teachers engage every child in class with the conviction that everyone can learn mathematics

Folk mathematics or mathematical folklore means theorems, definitions, proofs or mathematical facts or techniques that circulate among people by word of mouth but do not appear in print, either in books or in scholarly journals. While modern mathematics emphasizes formal and strict proofs of all given axioms practices in folk mathematics are usually understood intuitively and justified with examples. Folk math can also mean informal mathematics practice, as used in everyday life or by anthropology and psychology as it casts light on the perceptions and agreements of other cultures. Rural TamilNadu has a rich folklore of mathematical riddles, folkgames and folk art of koolam incorporating the concepts of number system. 


\section{OBJECTIVES OF THE STUDY}

- To determine the effectiveness of teaching mathematics using mathematical folklore over conventional method

- To compare the effectiveness of teaching mathematics using mathematical folklore with conventional method with particular reference to the objectives knowledge, understanding, application and skill

\section{HYPOTHESIS OF THE STUDY}

- There is a significant difference in teaching mathematics using mathematical folklore and conventional method

- There is a significant difference in teaching mathematics using mathematical folklore with conventional method with respect to the objectives knowledge, understanding, application and skill

- There is no significant difference in the achievement level between the experimental group and the control group of the pre-test

- There isa significant difference in the achievement level between the experimental group and the control group of the post-test

- There is a significant difference in the mean gain score between the experimental group and the control group

- There is a significant difference in the mean gain score between the experimental group and the control group of the pre-test

- There is a significant difference in the mean gain score between the experimental group and the control group of the post-test

- There is a significant difference in the pre-test score between the experimental group and the control group

- There is a significant difference in the post-test score between the experimental group and the control group

\section{SAMPLE}

Purposive sampling was used for the present study .40 students were selected from VII standard in Venkaiyammair Municipal Higher Secondary School at Erode District, Gobichettipalayam . These 40 students were randomly assigned to control and experimental groups with 20 as control group and 20 as experimental group.

The identity to the difference between the mean of these groups with regards to their achievement in mathematics as measured by the school examination and the scores of the pupils on their psychological variables a measured by the pre-test. All the above students were of the same age group.

\section{TOOLS USED FOR THIS STUDY}

Tool were prepared by the investigator, tool was constructed for 50 marks objective based achievement test for the present study, question paper given to every individual. 


\section{STATISTICAL TECHNIQUE USED FOR THE STUDY}

For the present study investigator used mean, standard deviation and t-test alone.

\section{TESTING OF THE HYPOTHESIS}

\section{Hypothesis-1}

There is no significant difference in the achievement level between the experimental group and the control group of the pre-test.

Table 1: shows t-test for achievement level between the experimental group and the control group of the pre-test

\begin{tabular}{|l|l|l|l|l|l|}
\hline Group & $\mathrm{N}$ & Mean & SD & t-value & Level of significant \\
\hline Control & 20 & 15.15 & 6.58 & 1.05 & 0.05 \\
\hline Experimental & 20 & 12.50 & 7.54 & & \\
\hline
\end{tabular}

The above table shows that t-value is 1.05 at 0.05 level is 1.96 is significant .hence the hypothesis is accepted. So the groups were having been equally matched before the treatment.

\section{Hypothesis-2}

There is a significant difference in the achievement- level of the experimental group and the control group of the post-test.

Table 2: shows t-test for achievement level of the experimental group and the control group of the post-test

\begin{tabular}{|l|l|l|l|l|l|}
\hline Group & $\mathrm{N}$ & Mean & SD & t-value & Level of significant \\
\hline Control & 20 & 10.65 & 5.98 & 7.95 & 0.05 \\
\hline Experimental & 20 & 35.55 & 12.65 & & \\
\hline
\end{tabular}

The above table shows that $\mathrm{t}$-value is 7.95 at 0.05 level is 1.96 is no significant .hence the hypothesis is rejected. Hence it is concluded that the effect of folk mathematics was better than the traditional method of teaching.

\section{Hypothesis-3}

There is significant difference in the mean gain score between the experimental group and the control group.

Table 3: shows t-test for difference between the mean scores of experimental group and the control group

\begin{tabular}{|l|l|l|l|l|l|}
\hline Group & $\mathrm{N}$ & Mean & SD & t-value & Level of significant \\
\hline Control & 20 & 15.65 & 5.98 & 7.14 & 0.05 \\
\hline Experimental & 20 & 38.00 & 12.65 & & \\
\hline
\end{tabular}


The above table shows that t-value is 7.14 at 0.05 level is 1.96 is no significant .hence the hypothesis is rejected. Hence it is concluded that the effect of folk mathematics was better than the traditional method of teaching.

\section{Hypothesis-4}

There is a significant difference in the mean gain score between the experimental group and the control group of the pre-test.

Table 4: shows t-test for difference between the mean scores of experimental group and the control group of the pre-test

\begin{tabular}{|l|l|l|l|l|l|}
\hline Group & $\mathrm{N}$ & Mean & SD & t-value & Level of significant \\
\hline Control & 20 & 12.81 & 7.36 & 4.02 & 0.05 \\
\hline Experimental & 20 & 33.68 & 12.27 & & \\
\hline
\end{tabular}

The above table shows that t-value is 4.02 at 0.05 level is 1.96 is no significant .hence the hypothesis is rejected. Hence there is no significant difference in the mean gain score between the experimental group and the control group of the pre-test.

\section{Hypothesis-5}

There is a significant difference in the mean gain score between the experimental group and the control group of the post-test

Table 5: shows t-test for difference between the mean gain scores of experimental group and the control group of the post-test

\begin{tabular}{|l|l|l|l|l|l|}
\hline Group & $\mathrm{N}$ & Mean & SD & t-value & Level of significant \\
\hline Control & 20 & 11.78 & 5.36 & 3.58 & 0.05 \\
\hline Experimental & 20 & 25.24 & 10.14 & & \\
\hline
\end{tabular}

The above table shows that t-value is 3.58 at 0.05 level is 1.96 is no significant hence the hypothesis is rejected. Hence there is no significant difference in the mean gain score between the experimental group and the control group of the post-test.

\section{Hypothesis-6}

There is a significant difference in the pre-test score between the experimental group and the control group.

Table 6: shows t-test for pre- test scores of experimental Group and the control group

\begin{tabular}{|l|l|l|l|l|l|}
\hline Group & $\mathrm{N}$ & Mean & SD & t-value & Level of significant \\
\hline Control & 20 & 15.2 & 7.20 & 3.85 & 0.05 \\
\hline Experimental & 20 & 17.1 & 6.74 & & \\
\hline
\end{tabular}


The above table shows that t-value is 3.85 at 0.05 level is 1.96 is no significant .hence the hypothesis is rejected. Hence there is no significant difference in the pre- test score between the experimental group and the control group.

\section{Hypothesis-7}

There is a significant difference in the post-test score between the experimental group and the control group.

Table 7: shows t-test for post- test scores of experimental group and the control group

\begin{tabular}{|l|l|l|l|l|l|}
\hline Group & $\mathrm{N}$ & Mean & SD & t-value & Level of significant \\
\hline Control & 20 & 38.9 & 12.04 & 5.02 & 0.05 \\
\hline Experimental & 20 & 42.4 & 7.64 & & \\
\hline
\end{tabular}

The above table shows that t-value is 5.02 at 0.05 level is 1.96 is no significant .hence the hypothesis is rejected. Hence there is no significant difference in the post- test score between the experimental group and the control group.

\section{MAJOR FINDINGS OF THE STUDY}

Thus below findings on the folk method of mathematics teaching at secondary level.

- There is no significant difference in the achievement level between the experimental group and the control group of the pre-test

- There is no significant difference in the achievement level between the experimental group and the control group of the post-test

- There is no significant difference in the mean gain score between the experimental group and the control group

- There is no significant difference in the mean gain score between the experimental group and the control group of the pre-test

- There is no significant difference in the mean gain score between the experimental group and the control group of the post-test

- There is no significant difference in the pre-test score between the experimental group and the control group

- There is no significant difference in the post-test score between the experimental group and the control group

\section{REFERENCES}

[1] Abidin, S.A. (1970), “The Role Of Schools In Characters Formation”, National Council of Educational Research And Training, New Delhi.

[2] Agarwal, J.C. (1998), "Essentials of Psychology”. New Delhi, Viskas Publishing House.

[3] Agarwal, S.M. (1992), "Solving In Mathematics". Edited By E.G. Belge, Washington, D.C. The Conference Board of the Mathematical Science.

[4] Best John, W.(1978), "Research in Education”. Practice - Hall Of India, New Delhi.

[5] Butler, C.H., Wren, F.L.(1960), "The Teaching Of Secondary Mathematics". Fourth Edition, Mc.Graw-Hill Book Company, New York. 
[6] Collier, Calhan, C., et.al (1969), "Teaching Mathematics in the Modern Elementary School”. The Mc.Graw-Hill Book Company, Collier-Macmillar Ltd., 1969.

[7] Golden, S. A. R. (2011). Strategy For Success Of Human Beings:-Time Management. Department Of BBA, St. Joseph's College, Trichy, 388, 390.

[8] Golden, S. A. R. (2011). Problems and Prospectus of Distance Learning. Bharathidhasan University, 343, 344.

[9] John, B., James, V.K.(1995), "Research In Education”. New Delhi. Prentice Hall of India.

[10] John, W.B. (1983), "Research in Education”. Delhi, Fifth Edition, and Prentice-Hall of India Private Limited.

[11] John, W.B., James, V.J.(1986), "Research in Education". Delhi, Fifth Edition, and Prentice-Hall of India Private Limited.

[12] Lokesh Koul (1984), "Methodology of Educational Research". Vikas Publish Publishing House, New Delhi.

[13] Regi, S. B., \& Golden, S. A. R. (2014). A Study On Educational Loan Availed By Students In Trichy City. Journal Of International Academic Research For Multidisciplinary (Jiarm), 2 (1).

[14] Sidhu, K.S.(1991), “The Teaching of Mathematics”. Sterling Publishers Pvt. Ltd., New Delhi.

[15] Stranmg, Ruth (1959), “An Introduction To Child Study”, New York, Macmillan Company, P.501. 